\title{
Public Preferences of Shared Autonomous Vehicles in Developing Countries: A Cross-National Study of Pakistan and China
}

\author{
Zhong Wang $\mathbb{D}^{1}{ }^{1}$ Muhammad Safdar $\left(\mathbb{D},{ }^{1}\right.$ Shaopeng Zhong $\left(\mathbb{D},{ }^{1}\right.$ \\ Jianrong Liu $\mathbb{D},^{2}$ and Feng Xiao $\mathbb{D}^{3}$ \\ ${ }^{1}$ School of Transportation and Logistics, Dalian University of Technology, Dalian 116024, China \\ ${ }^{2}$ School of Civil Engineering and Transportation, South China University of Technology, Guangzhou 510641, China \\ ${ }^{3}$ School of Business Administration, Southwestern University of Finance and Economics, Chengdu 611130, China \\ Correspondence should be addressed to Shaopeng Zhong; szhong@dlut.edu.cn and Jianrong Liu; ctjrliu@scut.edu.cn
}

Received 19 April 2021; Accepted 12 August 2021; Published 26 August 2021

Academic Editor: Ren-Yong Guo

Copyright ( 2021 Zhong Wang et al. This is an open access article distributed under the Creative Commons Attribution License, which permits unrestricted use, distribution, and reproduction in any medium, provided the original work is properly cited.

Shared autonomous vehicles (SAVs) are rapidly emerging as a viable alternative form of public transportation with the potential to provide adequate and user-friendly, on-demand services without having vehicle ownership. It has been argued that SAVs could revolutionize transportation systems and our current way of life. Although SAVs are likely to be introduced in developed countries first, there is little doubt that they would also have a significant effect and enormous market in developing nations. This study aimed to investigate the factors that influence public acceptance of SAVs, as well as the current public attitude toward SAVs, in two developing countries, namely, Pakistan and China. A stated preference survey was conducted to understand respondents' travel patterns, preferences, and sociodemographic data. A total of 910 valid responses were gathered: 551 from Lahore, Pakistan, and 359 from Dalian, China. A multinomial logit model and a mixed multinomial logit model with panel effect were used for data analysis. The results suggested that generic attributes, such as respondents' waiting time, travel time, and travel cost were found to be significant in both cities. The results indicate that sociodemographic characteristics, such as education, income, travel frequency in a week, and people who had driver's licenses, are significantly correlated with respondents' interest in using SAV in Lahore. The results also showed that people who had a private car indicated a greater interest in SAVs in Dalian. The study provides a new perspective to understand the public preferences toward SAVs in developing countries with different economies and cultures, as well as a benchmark for policymakers to make effective policies for the future implementation of SAVs.

\section{Introduction}

In recent years, autonomous vehicles (AVs) have emerged as a new form of transportation with the potential to improve traffic safety, efficiency, and urban environment. Shared autonomous vehicles (SAVs), also called robo-taxis or shuttles, can provide flexible and door-to-door service, with users able to summon SAVs using mobile device applications rather than having to find and walk to vehicles [1]. The amalgamation of AVs and shared mobility could further revolutionize personal transportation, given that SAVs provide the same level of convenience as more traditional forms of private transportation but without the same responsibilities and cost of ownership [2].

The US National Highway Traffic Safety Administration has reported that $90 \%$ of all vehicle accidents occur due to human errors [3]. Therefore AVs, by eliminating human errors, could considerably reduce the number of vehicle accidents $[4,5]$. Some researchers have suggested that the greenhouse gas emissions of SAVs could be as much as $90 \%$ less than those of the current passenger vehicles, and SAVs would dominate personal mobility options by 2050 [6]. SAVs could also overcome barriers associated with traditional dynamic riding services $[7,8]$. It has been proposed that the automatic relocation and pick-up of SAVs could enhance their availability and flexibility [9].

SAVs are likely to transform the structure of urban areas, towns, and neighborhoods $[7,10]$. The deployment of SAVs will reduce parking demands in urban centers, and enable the available space of parking to be used for various economic activities, infrastructure development, and other active and green transportation modes, such as walking, 
bicycling, and make the downtown area more attractive and sustainable [11]. The operational costs for SAVs are $\$ 0.13-0.50$ per mile, and the use of SAVs could lead to a $90 \%$ reduction of parking spaces $[12,13]$. It is estimated that each SAV could replace 3-14 conventional vehicles, given that SAVs could provide low-cost mobility services [14]. One latest study revealed that $10 \%$ of survey respondents were willing to move farther from the city center in the presence of AVs and SAVs in the next few years, while 15\% of the survey respondents indicated that they would likely move closer to the city center, which has an impact on travel behavior and land use [7]. The initiation of SAVs also offers an opportunity for employment and business growth in the charging zone and reduces the adverse impact of road congestion pricing $[15,16]$.

Despite the overwhelming benefits of SAVs, people are more curious about security, safety, interaction with pedestrians, and system failure [4]. SAVs might increase vehicle-miles traveled (VMT) by $8 \%$ to $17 \%$ for relocation, arrival, and departure purposes [9]. The main reasons for the increase in VMT are induced traffic demand and empty trips of SAVs [17]. The increase in VMT can be a cause of congestion and therefore impedes sustainable urban development [16]. A recent study suggests that SAVs can create bottlenecks for other road users by stopping on the curbside to take and drop passengers [18].

In developing countries such as China and Pakistan, rapid urbanization has profound negative effects in major metropolitan areas. Excessive urbanization causes a rise in travel demand and thus creates transportation problems. In particular, the absence of transportation infrastructure, insufficient public transportation, inadequate traffic management, and the lack of research and development have led to severe problems [19]. For example, Lahore, Pakistan, is plagued by severe traffic congestion. This is largely attributed to the inadequacy of the existing public transportation system, which is inefficient, disjointed, and accounts for only $20 \%$ of the mode share $[20,21]$. Traffic congestion has several negative consequences, such as increases in energy consumption, travel cost, travel time, air pollution, and traffic accidents [22]. The cost of traffic congestion in Lahore has been estimated at $\$ 519$ million per year [20]. China is also facing severe problems due to rapid urban growth and motorization. For example, in Dalian, private car ownership rose from 0.65 million in 2010 to 1.61 million in 2017. The modal share of private car travel increased from less than $15 \%$ in 2010 to $28.8 \%$ in 2016 . This increase in private car travel has caused several negative effects, such as increases in congestion, accidents, fuel consumption, air pollution [23], and public transportation ridership stagnation [23, 24]. However, technologies and policies are evolving very fast in China. Kuhnert et al. [25] stated that China was likely to have a similar level of technological development as the USA and Europe by 2030. Furthermore, they argued that the percentage of Chinese using traditional vehicles will decrease substantially by 2030 , due to a shift toward shared modes of transportation such as robo-taxis and shared bikes.

To the best of the authors' knowledge, there are very few studies performed to compare public attitudes toward SAVs in developing countries. This study meets the need by comparing the factors influencing public attitudes toward SAV adoption in two developing countries with different cultures and economies, namely, Pakistan and China. The objective of this study is to explore the public acceptance of SAVs in developing countries using a stated preference (SP) survey and discrete choice modeling techniques to identify the significant factors that can affect people's interest in SAVs in the presence of conventional modes of transportation. This is motivated by the fact that public acceptance is required for the rapid development and implementation of SAVs. The findings of this study provide a benchmark for policymakers tasked with making effective policies for the future implementation of SAVs in developing countries.

This study considers SAVs without pooled options, which provide the same level of privacy as a private car. On the contrary, SAVs with pooled options imply the sharing of a vehicle with strangers, which is a downside for many passengers [26]. The remainder of the paper is organized as follows. In Section 2, the existing literature on public attitudes toward SAVs is reviewed. Section 3 contains details of the data collection, questionnaire design, and model formulation. In Section 4, the results and discussion are presented. Finally, Section 5 comprises a summary of the major findings and conclusions.

\section{Literature Review}

SAVs are a relatively new concept in the field of surface transportation, which are not yet commercially available. In recent years, however, SAVs have become the subject of intense research. Numerous studies have been performed to analyze the potential effects of SAVs, as well as their operation and market penetration. Some studies have been conducted to determine people's transportation preferences in the hypothetical presence of SAVs, with these having been carried out in several different cultures and economies $[4,26-36]$. A summary of the existing literature on public preferences toward AVs and SAVs is provided in Table 1.

Most of the studies summarized in Table 1 collect data via online surveys, of which some have used online SP surveys. Various methodological approaches, such as multinomial logit model (MNL), nested logit model (NL), logit kernel or mixed logit model, and other regression models are often used for data analysis [4, 26, 29-32]. It is noted that the vast majority of these studies were conducted in developed countries and focused on autonomous vehicles, car-sharing service, and their combination with SAVs. Studies suggest that sociodemographic attributes of people (age, education, gender) and trip attributes (travel time, travel cost, waiting time) are influencing factors in the adoption of SAVs [4, 26, 29, 32]. Similarly, safety, comfort, and SAVs' membership costs are the key predictors that influence the public travel mode preferences toward SAVs [4, 30, 33, 34]. Likewise, other factors, such as having a driver's license and owning a private car, have also been found to influence users' preferences for AVs and SAVs [26, 29]. 
TABLE 1: Summary of current studies on public opinions and preferences toward AVs and SAVs.

\begin{tabular}{|c|c|c|c|c|}
\hline Authors & Study area & $\begin{array}{l}\text { Respondents } \\
\text { (n) }\end{array}$ & Survey type & Methodology \\
\hline $\begin{array}{l}\text { Haboucha } \\
\text { et al. [4] }\end{array}$ & The USA and Israel & 721 & $\begin{array}{c}\text { Online SP } \\
\text { survey }\end{array}$ & Logit kernel model \\
\hline $\begin{array}{l}\text { Winter et al. } \\
\text { [26] }\end{array}$ & Netherlands & 732 & $\begin{array}{c}\text { Online SP } \\
\text { survey }\end{array}$ & $\begin{array}{c}\text { Multinomial logit } \\
\text { model and nested } \\
\text { logit model }\end{array}$ \\
\hline
\end{tabular}

(i) $75 \%$ of the respondents expressed willingness to use SAVs if the services were completely free.

(ii) Young and highly educated individuals were more willing to use SAVs.

(i) Individuals who did not have access to car-sharing expressed more of a preference for free-floating car-sharing.

(ii) Early adopters of mobility trends were more likely to be willing to use SAVs over all other modes of transportation.

(iii) Normal and late adopters unambiguously rejected the notion of using SAVs.

(iv) Gender, driver's license, level of education, and possession of at least one private car in the household were also significant factors influencing the willingness to use SAVs.

(i) Respondents realized fewer crashes as primary benefits of AVs and system failure is one of the main concerns.

Bansal et al. [27] Austin, USA

347

Online

survey
Order probit model and descriptive statistics (ii) Males who are aware of technology, higher-income individuals, those who had experience with more crashes, and those who lived in urban areas with strong interest and higher acceptance for the new technologies had minimum dependence on other adoption rates.

(i) $47.14 \%$ of users were willing to share their ride and they agreed to wait on average of $12.96 \pm 8.8$ minutes for shared

Cools et al. [28]

Belgium

661

Stated adoption

Regression models survey autonomous vehicles to pick them up. (ii) $47.45 \%$ of the individuals were willing to share their private daily trip schedule for zero waiting time.

(i) Young individuals, and people who traveled by public transportation, private cars, or walked frequently, were more

Krueger et al. [29]

Australia

435
Online SP survey

Mixed logit model willing to use SAVs.

There was a greater willingness to use SAVs for medical trips and shopping trips. (iii) Travel cost, travel time, and waiting time were key factors influencing the willingness to use SAVs as a riding service.

(i) Vehicle accident history, current travel characteristics, and gender significantly influenced the willingness to relinquish an existing vehicle if SAVs were available. 
TABLE 1: Continued.

\begin{tabular}{|c|c|c|c|c|c|}
\hline Authors & Study area & $\begin{array}{c}\text { Respondents } \\
\text { (n) }\end{array}$ & Survey type & Methodology & Major findings \\
\hline $\begin{array}{l}\text { Wadud and } \\
\text { Huda [31] }\end{array}$ & $\begin{array}{l}\text { Multiple countries such as } \\
\text { Bangladesh, the United } \\
\text { Kingdom, the USA, and } \\
\text { others }\end{array}$ & 621 & $\begin{array}{l}\text { Online } \\
\text { survey }\end{array}$ & $\begin{array}{l}\text { Mixed-effects } \\
\text { ordered logistic } \\
\text { regression }\end{array}$ & $\begin{array}{l}\text { (i) Users were more likely to participate in } \\
\text { other nondriving activities while riding in } \\
\text { AVs, depending on trip direction and } \\
\text { purpose. } \\
\text { (ii) The time spent in AVs was perceived to } \\
\text { be more worthwhile relative to the existing } \\
\text { modes of transportation. }\end{array}$ \\
\hline Yap et al. [32] & Netherlands & 761 & $\begin{array}{l}\text { Online SP } \\
\text { survey }\end{array}$ & Mixed logit model & $\begin{array}{l}\text { (i) In-vehicle time was perceived more } \\
\text { negatively for AVs than for human-driven } \\
\text { cars. }\end{array}$ \\
\hline $\begin{array}{l}\text { Kyriakidis } \\
\text { et al. [33] }\end{array}$ & 109 countries & 5,000 & $\begin{array}{l}\text { Online } \\
\text { survey }\end{array}$ & $\begin{array}{l}\text { Descriptive } \\
\text { statistics and } \\
\text { Spearman } \\
\text { correlation }\end{array}$ & $\begin{array}{l}\text { (i) Respondents were more interested in } \\
\text { manual driving. } \\
\text { (ii) Respondents had a high concern about } \\
\text { software hacking and moderate concern } \\
\text { about legal issues and safety. }\end{array}$ \\
\hline $\begin{array}{l}\text { Nordhoff } \\
\text { et al. [34] }\end{array}$ & 116 countries & 7,755 & $\begin{array}{l}\text { Online } \\
\text { survey }\end{array}$ & $\begin{array}{l}\text { Descriptive } \\
\text { statistics and } \\
\text { Spearman } \\
\text { correlation }\end{array}$ & $\begin{array}{l}\text { (i) People were happier riding AVs. } \\
\text { (ii) Self-reported acceptance of AVs was } \\
\text { highly determined by domain-specific } \\
\text { attitudes than by sociodemographic } \\
\text { characteristics. }\end{array}$ \\
\hline $\begin{array}{l}\text { Sanaullah } \\
\text { et al. [35] }\end{array}$ & Pakistan & 99 & $\begin{array}{l}\text { Online } \\
\text { survey }\end{array}$ & $\begin{array}{l}\text { Descriptive } \\
\text { statistics }\end{array}$ & $\begin{array}{l}\text { (i) } 88.9 \% \text { of respondents had heard about } \\
\text { AVs and } 11.1 \% \text { did not know about AVs. } \\
\text { (ii) In terms of interest in AVs technology, } \\
74.7 \% \text { had high interest, and the rest of the } \\
24.3 \% \text { had no interest in AVs technology. } \\
\text { (iii) } 65.7 \% \text { of respondents thought that } \\
\text { AVs would be safe for a ride. } \\
\text { (iv) Around } 34.6 \% \text { of respondents claim } \\
\text { that it would be comfortable for a ride } \\
\text { when AVs are operational on-road } \\
\text { together with private cars. } \\
\text { (v) } 61.6 \% \text { of respondents were found to be } \\
\text { uncomfortable with AVs due to } \\
\text { interacting with human-driven vehicles } \\
\text { on the road. }\end{array}$ \\
\hline $\begin{array}{l}\text { Schoettle and } \\
\text { Sivak [36] }\end{array}$ & China, India, and Japan & 1,722 & $\begin{array}{l}\text { Online } \\
\text { survey }\end{array}$ & $\begin{array}{l}\text { Descriptive } \\
\text { statistics }\end{array}$ & $\begin{array}{l}\text { (i) More than } 84 \% \text { of individuals in India } \\
\text { and China, whereas } 43 \% \text { of individuals in } \\
\text { Japan had positive opinions toward AVs. } \\
\text { (ii) Regarding the adoption of AVs as } \\
\text { personal vehicles, the Chinese and Indian } \\
\text { respondents indicated a large proportion } \\
\text { of acceptance of } 76 \% \text { and } 80 \% \text {, } \\
\text { respectively, as compared to } 41 \% \text { of } \\
\text { Japanese respondents. }\end{array}$ \\
\hline
\end{tabular}

The conclusions from previous studies are not necessarily applicable to developing countries, where urbanization and developmental levels, cultural norms, and transportation rationales may be vastly different. Therefore, examining public attitudes toward SAVs in developing countries can assist in making the analysis more relevant in terms of the expected future technological landscape in this domain. In essence, an SP survey design that concentrates on a respondent's current travel selections and rationality may be able to increase our understanding of traveler preferences for SAVs. This current study intends to add valuable inputs from developing countries, which would subsequently help policymakers to make more rigorous decisions about SAVs worldwide. 


\section{Methodology}

3.1. Study Area. In this research, we consider two cities: Lahore, Pakistan, and Dalian, China. Lahore is the capital of the Punjab Province, and the second megacity of Pakistan, with a population of 11.13 million and an area of $1,792 \mathrm{~km}^{2}$ [37]. It comprises $12.7 \%$ of the total urban population of Pakistan. In 2017, it had a per capita GDP of approximately $\$ 5,855$. Lahore is a hub for educational, medical, and industrial employment opportunities, and contains various other allied facilities. Together, these factors place enormous demands on the road network [22], and consequently, Lahore is at the forefront of public transportation and infrastructure development in Pakistan. The first bus rapid transit system (BRT) in Pakistan, the Lahore metro bus system, was launched in 2013. An average of 135,000 people travel on the BRT every day [21].

Dalian is located on the southern tip of the Liaodong Peninsula in northeast China, with the Bohai Sea to the west and the Yellow Sea to the east. Dalian is one of the most popular business areas in China, a tourist destination, and a distribution hub for goods and materials, with the Dalian container port linking more than 20 international oceanshipping routes $[23,24]$. Dalian is a heavily developed industrial area of China, with a population of 6.98 million and a total administrative area of $13,237 \mathrm{~km}^{2}$. In 2017 , the GDP per capita in Dalian was approximately $\$ 14,816$. It is a flexible and innovative city in terms of public transportation, with four subway lines, one BRT route, two trolley bus lines, and approximately 130 conventional bus lines. The summary statistics for Lahore and Dalian are provided in Table 2 [23].

The findings of previous studies have indicated that major metropolitan cities in developing countries face significant negative effects related to urbanization, such as increasing car ownership leading to traffic congestion, environmental problems, and land-use problems [21, 23, 38-40]. Dalian and Lahore have different levels of development, different economies, and different cultures. However, they have similar transportation systems and public transportation policies. In both cities, private cars symbolize freedom and mobility, while the possibilities for expanding road infrastructure are limited. Both cities have invested heavily in promoting and optimizing public transportation systems. Moreover, neither city has car restrictions nor congestion charges. Finally, Lahore and Dalian are broadly representative of other cities in Pakistan and China, respectively, in terms of their travel patterns $[21,23,40]$.

3.2. Design of the SP Survey. SP surveys have been widely used in the field of transportation to analyze people's travel behavior, including their preferences for alternative forms of transportation that are not yet available [41]. In the SP survey, various hypothetical scenarios are presented to respondents, who then select their preferred choice(s) regarding each scenario from a finite set of attributes and alternatives [42-44]. SAVs are not yet available in the public transportation sector, and thus choice behavior and preferences toward SAVs cannot be observed. An SP survey was therefore conducted to elicit the respondents' willingness to use SAVs.

The SP survey questionnaire in this study had three sections. In the first section, the respondents were familiarized with SAVs, via a general description and a pictorial representation in Figure 1, and were asked whether they possessed a private car and a driver's license. In addition, the respondents were asked questions regarding their technological interests, awareness of SAVs, and inclination to use existing dynamic riding services. In the second section, respondents were asked to select their preferred mode of transportation from a list of possible alternatives. In the third section, the respondents were asked questions relating to sociodemographic characteristics, namely, gender, age, educational attainment, employment, and monthly income.

3.3. Alternatives and Attributes of Choice Experiments. Four alternatives (i.e., modes of transportation) and four attributes were presented in the SP survey questionnaires to respondents. For Lahore, the alternatives were personal cars, conventional taxis, minibuses, and SAVs. For Dalian, the alternatives were personal cars, conventional taxis, conventional buses, and SAVs. Our study focuses on SAVs with level 5 autonomy as defined by the Society of Automotive Engineers, which means that automated vehicles complete all driving tasks autonomously, without any human intervention [32]. For both cities, the four attributes were walking distance, waiting time, travel time, and travel cost. These attributes were selected as they were considered the main factors that influence people's decisions on whether to travel by private car or by public transportation. To aid understanding of different scenarios, and elicit more realistic responses, pictorial versions of each alternative were presented to respondents. Each attribute was assigned three levels, and thus the total factorial was $3^{13}$. The levels of the attributes for each of the alternatives in Lahore and Dalian are provided in Tables 3 and 4, respectively.

To increase the realism of the choices, the levels of the attributes of the hypothetical alternatives were pivoted around the levels of the attributes of the revealed preferences [29]. For both cities, the levels of the attributes were based on traveling a distance of $10 \mathrm{~km}$ in the central business district. This is particularly appropriate in Lahore, where the majority of the population lives within a $7-8 \mathrm{~km}$ radius of the city center [45]. The travel time for personal cars was based on the average speed of cars in both cities. Similarly, the travel times for conventional taxis, minibuses, and conventional buses were based on their average speeds. The travel cost of a personal car was calculated by considering the fuel, depreciation, maintenance, and miscellaneous (e.g., parking, carwash, tolls) costs. This is somewhat different from previous studies, in which fuel cost and parking cost were considered separately, but the maintenance, depreciation, and miscellaneous costs were ignored. The travel costs of the conventional taxi, conventional bus, and minibus were calculated from existing fares. Finally, the travel time and travel cost for SAVs were taken from existing research. 
TABle 2: Features of Lahore and Dalian.

\begin{tabular}{|c|c|c|}
\hline Features & Lahore & Dalian \\
\hline Area & $\begin{array}{l}\text { (i) Administrative area: } 1,792 \mathrm{~km}^{2} \\
\text { (ii) Built-up area: } 685 \mathrm{~km}^{2} \\
\text { (iii) Area served by public transportation: } 280.36 \mathrm{~km}^{2} \\
\text { (40.93\% of the total built-up area) }\end{array}$ & $\begin{array}{l}\text { (i) Administrative area: } 13,325 \mathrm{~km}^{2} \\
\text { (ii) Built-up area: } 621 \mathrm{~km}^{2} \\
\text { (iii) Density of the transit network in the built- } \\
\text { up area: } 2.34 \mathrm{~km} / \mathrm{km}^{2}\end{array}$ \\
\hline Population & 11.13 million & 6.98 million \\
\hline $\begin{array}{l}\text { Daily number of } \\
\text { passengers }\end{array}$ & 1.11 million & 2.535 million \\
\hline $\begin{array}{l}\text { Public transportation } \\
\text { routes }\end{array}$ & $\begin{array}{l}\text { (i) } 1 \text { BRT route } \\
\text { (ii) } 54 \text { regular bus and minibus routes operated by Lahore } \\
\text { transportation company } \\
\text { (iii) Qingqi rickshaws as paratransit }\end{array}$ & $\begin{array}{l}145 \text { transit lines, including: } \\
\text { (i) } 1 \text { BRT route } \\
\text { (ii) } 30 \text { minibuses } \\
\text { (iii) } 108 \text { regular bus routes } \\
\text { (iv) } 2 \text { trolleybus lines } \\
\text { (v) } 4 \text { metro lines }\end{array}$ \\
\hline
\end{tabular}

Number of private cars

per 1,000

192 vehicles

231 vehicles

residents (2016)

\begin{tabular}{lll}
\hline & (i) $20 \%$ public transportation & (i) $40 \%$ public transportation \\
Mode share of travel & (ii) $62 \%$ motorcycle & (ii) $28.8 \%$ private car \\
& (iii) $8 \%$ private car & \\
\hline
\end{tabular}

GDP per capita (2017) $\$ 5,855$ $\$ 14,816$

A Taguchi fractional factorial experimental design was used to implement the choice experiments, using Minitab software. This design enables a subset of all possible scenarios to be created. In this case, a total of 27 scenarios were generated. An example of a scenario for Lahore is depicted in Figure 2, and another example of a scenario for Dalian is depicted in Figure 3. To achieve more realistic responses, the 27 scenarios were divided into nine blocks of three each. Each respondent thus only had to consider three scenarios.

3.4. Data Collection. In this study, data were collected from respondents in Lahore, Pakistan, and Dalian, China, respectively, with Lahore respondents surveyed first. The questionnaire was devised and uploaded in English as a Google Form. Hyperlinks were generated for each of the nine experimental blocks. The online questionnaire was then disseminated via social media and emails to randomly selected residents in Lahore. This strategy enables rapid delivery, randomly selected respondents, easy switching between scenarios, and is inexpensive [46]. The questionnaires were distributed to the potential respondents in nine separate groups, who had a fortnight to complete the questionnaires from the date of receipt. The data were collected between April 10, 2019 and July 5, 2019, with a total of 551 valid responses being received. Each respondent considered three scenarios, and thus the total number of observations was 1,653 . A summary of the sociodemographic characteristics of the respondents is provided in Table 5.

In the second phase, data were collected in Dalian. The questionnaire was devised, then translated into Chinese, and uploaded as a Wenjuanxing Form (https://www.wjx.cn). Nine hyperlinks and nine QR codes were generated for the nine experimental blocks. Fliers containing the formal greeting from the questionnaire, one of the QR codes, and an outline of the study objectives were designed. The questionnaire was then randomly distributed by sharing the fliers online via social media platforms WeChat and QQ, and printed fliers were also distributed manually within the central business district, with the help of colleagues and friends. The fliers were distributed in nine separate groups, and respondents were allowed two weeks to complete the questionnaires from the date of receipt. The data were collected between July 15, 2019 and October 30, 2019, and a total of 359 valid responses were received. Each respondent considered three scenarios, and the total number of observations was therefore 1,077 . A summary of the sociodemographic characteristics of the respondents is provided in Table 5. The high percentage of students and younger respondents in both cities may be attributed to the fact that unemployed, less educated, and elderly people are usually less approachable through online surveys.

Nontrading behavior is one of the major drawbacks of online SP surveys. Nontrader implies that the respondent always selects the same alternative for each choice scenario of preference. This behavior of respondents may be attributed to several factors. First, a respondent may have an extreme preference for one alternative. Second, a respondent usually gets bored and does not pay full attention to the survey. Third, a respondent makes strategic or political decisions. However, it is a difficult task to distinguish the three causes of nontrading behavior. Some researchers have reported that nontrader behaviors can also affect the marginal utility coefficients [47]. The current study has been conducted on traders and nontrader groups. However, for the reason of concision, we are only focused on the traders' group.

In the Lahore survey, 61 out of the 612 respondents (9.97\%) represented nontrading behavior. 38\% of nontrader respondents chose SAVs, $31 \%$ chose a private car, $15 \%$ chose a conventional taxi, and $16 \%$ chose the minibus. Most nontraders were highly educated with a bachelor's and a 


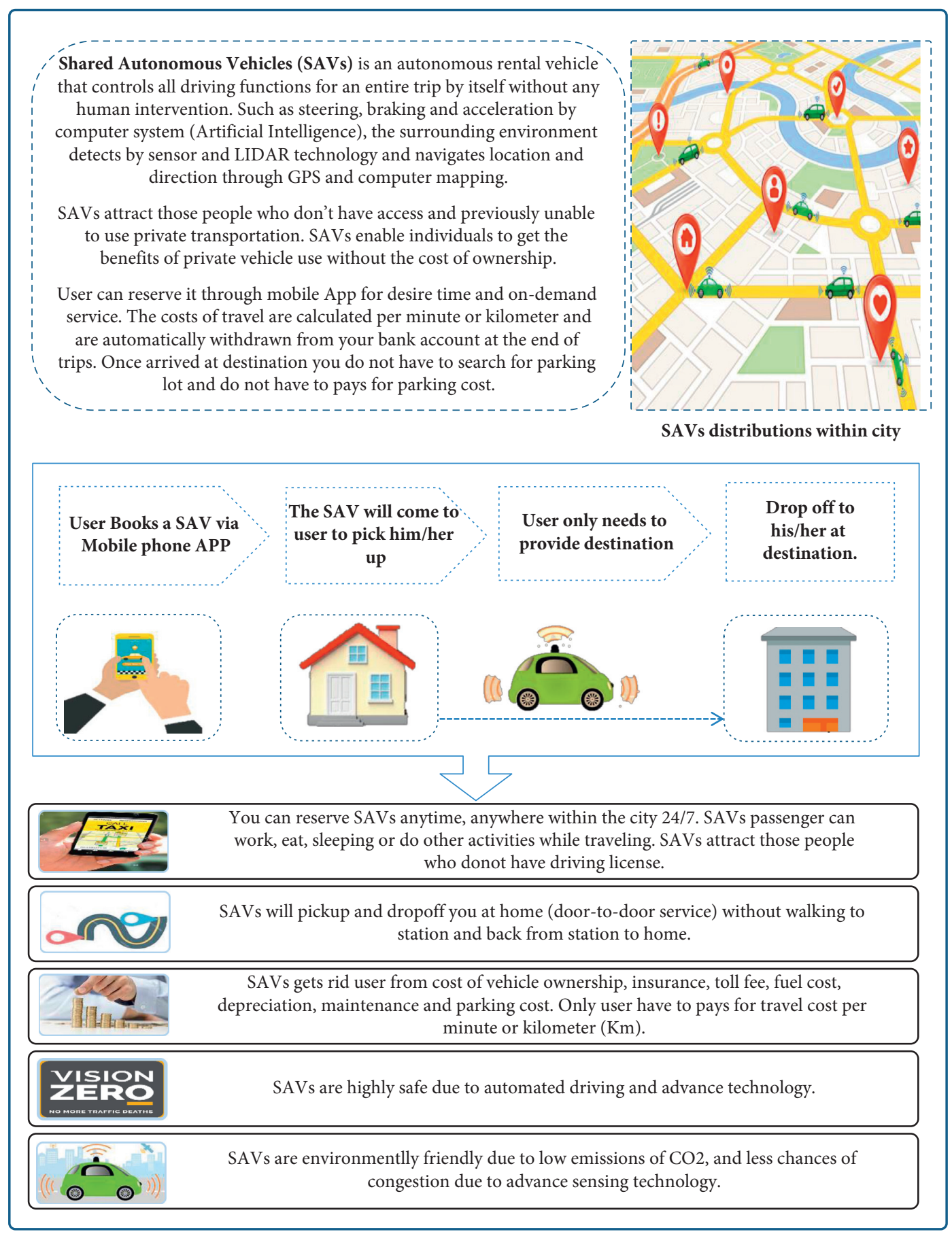

Figure 1: Profile of SAVs in Lahore and Dalian SP surveys.

TABLE 3: Levels of the attributes for each of the alternatives in Lahore.

\begin{tabular}{lcccc}
\hline \multirow{2}{*}{ Alternatives } & & \multicolumn{2}{c}{ Attributes } \\
& Walking distance $(\mathrm{m})$ & Waiting time (min) & Travel time (min) & Travel cost (PKR) \\
\hline SAV & NA & $1,4,7$ & $15,20,25$ & $350,450,550$ \\
Personal car & NA & NA & $15,20,25$ & $300,350,400$ \\
Conventional taxi & $300,500,700$ & $2,5,8$ & $20,25,30$ & $450,550,650$ \\
Mini bus & $400,800,1200$ & $5,10,15$ & $45,55,65$ & $25,35,45$ \\
\hline
\end{tabular}

$(\mathrm{NA}=$ not applicable, $\mathrm{PKR}=$ Pakistani Rupee, $1 \mathrm{PKR}=0.007$ USD in April 2019). 
TABLe 4: Levels of the attributes for each of the alternatives in Dalian.

\begin{tabular}{lcccc}
\hline \multirow{2}{*}{ Alternatives } & & \multicolumn{2}{c}{ Attributes } & \\
& Walking distance $(\mathrm{m})$ & Waiting time $(\mathrm{min})$ & Travel time (min) & Travel cost $(\mathrm{CNY})$ \\
\hline SAV & NA & $1,4,7$ & $15,25,35$ & $25,30,35$ \\
Personal car & NA & NA & $20,30,40$ & $20,25,30$ \\
Conventional taxi & $100,300,500$ & $2,5,8$ & $20,30,40$ & $30,35,40$ \\
Mini bus & $300,600,900$ & $4,8,12$ & $40,50,60$ & $1,2,3$ \\
\hline
\end{tabular}

(CNY = Chinese Yuan, 1 CNY = 0.146 USD in July 2019).

Q. Which mode would you prefer for going to school/working trip in peak hours?

\begin{tabular}{|c|c|c|c|c|c|}
\hline \multicolumn{2}{|c|}{ Attributes } & $\begin{array}{c}\text { Walking } \\
\text { Distance } \\
(\mathbf{m})\end{array}$ & $\begin{array}{c}\text { Waiting } \\
\text { Time } \\
(\mathbf{m i n})\end{array}$ & $\begin{array}{c}\text { Travel } \\
\text { Time } \\
(\mathbf{m i n})\end{array}$ & $\begin{array}{c}\text { Travel } \\
\text { Cost } \\
(\mathbf{P K R})\end{array}$ \\
\hline $\begin{array}{c}\text { Shared } \\
\text { Vehicle (SAV) }\end{array}$ & 0 & 1 & 15 & 350 \\
\hline & Personal Car & 0 & 0 & 15 & 300 \\
\hline & $\begin{array}{c}\text { Conventional } \\
\text { Taxi }\end{array}$ & 300 & 4 & 20 & 450 \\
\hline
\end{tabular}

FIgURE 2: Example of a choice experiment in Lahore.

Q. Which mode would you prefer for going to school/working trip in peak hours?

\begin{tabular}{|c|c|c|c|c|c|}
\hline \multicolumn{2}{|c|}{ Attributes } & $\begin{array}{c}\text { Walking } \\
\text { Distance } \\
(\mathbf{m})\end{array}$ & $\begin{array}{c}\text { Waiting } \\
\text { Time } \\
(\mathbf{m i n})\end{array}$ & $\begin{array}{c}\text { Travel } \\
\text { Time } \\
(\mathbf{m i n})\end{array}$ & $\begin{array}{c}\text { Travel } \\
\text { Cost } \\
(\mathbf{C N Y})\end{array}$ \\
\hline $\begin{array}{c}\text { Shared } \\
\text { Autonomous } \\
\text { Vehicle (SAV) }\end{array}$ & 0 & 1 & 15 & 25 \\
\hline & Personal Car & 0 & 0 & 20 & 20 \\
\hline & $\begin{array}{c}\text { Conventional } \\
\text { Taxi }\end{array}$ & 100 & 2 & 20 & 30 \\
\hline
\end{tabular}

Figure 3: Example of a choice experiment in Dalian.

master's degree or above, employed people, and high earners having an income of more than $50,000 \mathrm{PKR} / \mathrm{month}$. In terms of age, $51 \%$ of nontraders were under 45 years old, while the rest were older than 45 years. In terms of gender, 31 were men and 30 were women. Furthermore, 18 out of the 31 male respondents have always opted for private cars, and 18 out of the female respondents have preferred SAVs.

In the Dalian survey, 87 out of the 446 respondents (19.5\%) showed nontrading behavior. $29 \%$ of nontrader respondents chose SAVs, $61 \%$ chose a private car, $1 \%$ chose a conventional taxi, and $9 \%$ chose the conventional bus. Most of the nontrader respondents were men, younger people, highly educated with a bachelor's and a master's degree or above, students, or lower-income people. A total of 61 nontrader respondents were men, and 45 of them always opted for private cars. Similarly, for younger people (age $18-25), 35$ out of 53 respondents always opted for private cars. In terms of employment, 32 out of 45 student respondents opted for private cars. 34 out of the 47 respondents whose income was less than 3,000 CNY/month always opted for private cars.

Based on the above descriptive results of nontraders, it is noted that the majority of the nontraders were employed, highly educated, and high-income people in both cities. In this study, the nontraders had an equal preference for SAVs and private cars in Lahore. However, the nontraders in Dalian had a strong preference for private cars. After excluding the nontrader respondents from the sample, the remaining 551 and 359 trader respondents from Lahore and Dalian were used for the discrete choice analysis.

3.5. Model Formulation. Discrete choice models are the most applicable techniques to examine travelers' preferences toward transportation mode choice under the assumption of 
TABle 5: A summary of the sociodemographic characteristics of respondents in Lahore and Dalian.

\begin{tabular}{|c|c|c|c|}
\hline \multirow{2}{*}{ Parameters } & \multirow{2}{*}{ Category } & \multicolumn{2}{|c|}{ Proportion of respondents } \\
\hline & & Lahore $(N=551)$ & Dalian $(N=359)$ \\
\hline \multirow{2}{*}{ Gender } & Male & $66 \%$ & $48 \%$ \\
\hline & Female & $34 \%$ & $52 \%$ \\
\hline \multirow{4}{*}{ Employment } & Student & $32 \%$ & $57 \%$ \\
\hline & Unemployed & $5 \%$ & $10 \%$ \\
\hline & Employed & $59 \%$ & $29 \%$ \\
\hline & Entrepreneur & $4 \%$ & $4 \%$ \\
\hline \multirow{6}{*}{ Age groups } & $18-25$ & $17 \%$ & $55 \%$ \\
\hline & $26-35$ & $34 \%$ & $18 \%$ \\
\hline & $36-45$ & $17 \%$ & $7 \%$ \\
\hline & $46-55$ & $24 \%$ & $12 \%$ \\
\hline & $56-70$ & $7 \%$ & $7 \%$ \\
\hline & $>70$ & $1 \%$ & $1 \%$ \\
\hline \multirow{4}{*}{ Educational Attainment } & Under high school & $6 \%$ & $2 \%$ \\
\hline & High school & $31 \%$ & $11 \%$ \\
\hline & Bachelor's degree & $41 \%$ & $37 \%$ \\
\hline & Master's degree and above & $22 \%$ & $50 \%$ \\
\hline \multirow{5}{*}{ Monthly income (PKR) } & $<25,000$ & $18 \%$ & \multirow{5}{*}{ NA } \\
\hline & $26,000-50,000$ & $28 \%$ & \\
\hline & $51,000-75,000$ & $39 \%$ & \\
\hline & $76,000-100,000$ & $11 \%$ & \\
\hline & $>100,000$ & $4 \%$ & \\
\hline \multirow{5}{*}{ Monthly income (CNY) } & $<3,000$ & \multirow{5}{*}{ NA } & $57 \%$ \\
\hline & $3,001-6,000$ & & $14 \%$ \\
\hline & $6,001-10,000$ & & $14 \%$ \\
\hline & $10,001-15,000$ & & $11 \%$ \\
\hline & $>15,000$ & & $4 \%$ \\
\hline \multirow{6}{*}{ Travel in one week (days) } & 1 & $6 \%$ & $22 \%$ \\
\hline & 2 & $12 \%$ & $15 \%$ \\
\hline & 3 & $21 \%$ & $21 \%$ \\
\hline & 4 & $36 \%$ & $11 \%$ \\
\hline & 5 & $23 \%$ & $26 \%$ \\
\hline & None & $2 \%$ & $5 \%$ \\
\hline \multirow{2}{*}{ Car ownership } & Yes & $50 \%$ & $39 \%$ \\
\hline & No & $50 \%$ & $61 \%$ \\
\hline \multirow{2}{*}{ Driver's license } & Yes & $53 \%$ & $66 \%$ \\
\hline & No & $47 \%$ & $34 \%$ \\
\hline
\end{tabular}

the random utility maximization framework. It is assumed that individuals choose the alternative over the course of alternatives that has the maximum utility for them [10]. Various discrete choice models have been used to analyze travelers' preferences for AVs and SAVs, such as the multinomial logit model, the nested logit model, and the mixed logit model $[4,26,29,32]$. In this study, the multinomial logit (MNL) model and the mixed multinomial logit (MMNL) model with panel effect were used.

3.5.1. Multinomial Logit Model. The MNL model is frequently used to interpret and calibrate mode-choice data [48]. In the MNL model, the utility is decomposed into two parts, namely, the systematic utility and the random error:

$$
U_{\text {in }}=V_{\text {in }}+\varepsilon_{\text {in }},
$$

where $U_{\text {in }}$ is the overall utility of the alternative $i$ to the decision maker $n, \varepsilon_{\text {in }}$ is the unobserved error component of utility, and $V_{\text {in }}$ is the systematic utility function. The systematic utility function is further decomposed as

$$
V_{i n}=\sum_{k=1}^{K} \beta_{i k}^{\text {alt }} x_{k n}+\sum_{m=1}^{M} \beta_{i m}^{\text {ind }} x_{m n},
$$

where $\beta_{i k}^{\text {alt }}$ are the parameters of alternative-specific attributes, $\beta_{i m}^{\text {ind }}$ are the parameters of individual-related variables, $x$ is the explanatory variable, $K$ is the total number of alternative-related parameters in the model, and $M$ is the total number of individual-related parameters in the model.

The probability of each individual $n$ choosing alternative $i$ from a set of alternatives $j(j=1,2, \ldots, J)$ can be estimated via 


$$
P_{\text {in }}=\frac{\exp \left(V_{\text {in }}\right)}{\sum_{j=1}^{J} \exp \left(V_{\text {in }}\right)}
$$

3.5.2. Mixed Multinomial Logit Model. The MMNL model generalizes the MNL model by allowing the coefficients $\beta$ to be random. In particular, it is now assumed that $\beta$ is distributed according to $\beta \sim f(\beta)$, for some density $f(\beta)$. In this case, conditional on $\beta$, the probability of each individual $n$ choosing alternative $i$ from a set of alternatives $j(j=1,2$, $\ldots, J)$ is given by

$$
L_{\text {in }}(\beta)=\frac{\exp \left(V_{\text {in }}(\beta)\right)}{\sum_{j=1}^{J} \exp \left(V_{j n}(\beta)\right)},
$$

where it is now made explicit that the systematic utility function $V_{\text {in }}$ depends on the parameter $\beta$, by writing $V_{\text {in }}=$ $V_{\text {in }}(\beta)$. As $\beta$ is now random and not known, the (unconditional) choice probability is now the integral of the previous probability over the density of $\beta[49,50]$, as given by

$$
P_{\text {in }}=\int L_{\text {in }}(\beta) f(\beta) \mathrm{d} \beta \text {. }
$$

The choice probabilities are thus considered as a mixture of the logit function evaluated over the values of parameters $\beta$, with $f(\beta)$ the density of the parameters. This model does not constrain $\beta$ to follow a normal distribution, unlike the probit model, and thus can be used with any other distribution (e.g., triangular, uniform, and lognormal). In this sense, it is considered a more powerful and flexible model in treating the variances and correlations of the random component.

\section{Results and Discussion}

4.1. Descriptive Statistics. In the first section of the survey questionnaire, respondents were asked questions regarding their awareness of SAVs, technological interests, and inclination to use existing dynamic riding services. Regarding awareness of SAVs, 75\% (81\%) of respondents had heard of SAVs in Lahore (Dalian), as shown in Figure 4. The technological interest of the respondents in advanced technology was analyzed on a Likert scale (extremely interested, moderately interested, slightly interested, and not at all interested). Individuals' interest in advanced technology was high. Approximately $71 \%$ and $86 \%$ of respondents in Lahore and Dalian had extreme and moderate interest, respectively. Figure 5 shows that individuals interested in new technology were more willing to adopt SAVs for schooling and working trips than other trips in both cities. This suggests that the "automation" of vehicles would be more effective during peak hours of work and schooling. This finding is in line with the previous study that early adopters showed more interest in new technology. The diffusion of innovation theory by Roger Everett's classic model has been divided into five categories; innovators, early adopters, early majority, late majority, and laggards. According to the diffusion of innovation theory, early adopters embrace technology more

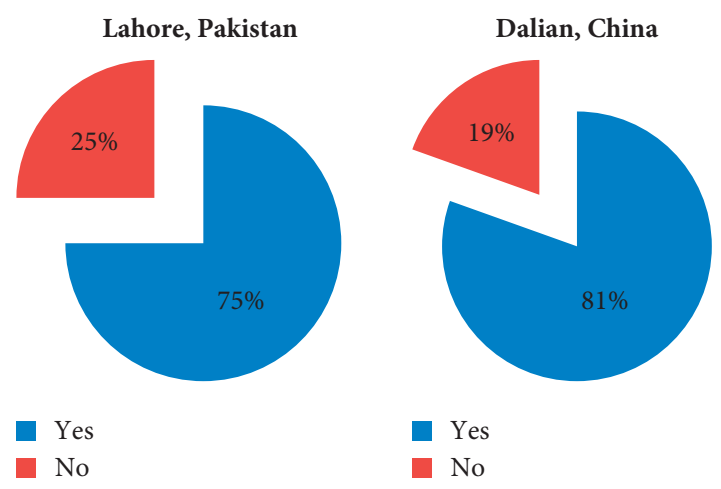

FIgURE 4: Awareness of respondents about SAVs in Lahore and Dalian.

rapidly [51]. The results of individuals interested in new technology and their preference for shopping and social trips are shown in Figure 6 and 7.

Finally, regarding the inclination of the respondents to use existing dynamic riding services, e.g., Careem or Uber in Pakistan and Didi in China, 82\% (88\%) had used these services in Lahore (Dalian). In addition, as shown in Figure 8 , the individuals who use dynamic riding services were willing to adopt SAVs and private cars (conventional bus) for commuting to school and the workplace as compared to other trips in Lahore (Dalian). The results of individuals who used dynamic riding service and their preference for shopping and social trips are shown in Figure 9 and 10. Based on these descriptive results, respondents had a slightly higher preference for SAVs with sharing systems rather than automation in both cities, as shown in Figures 5 and 6, and Figures 8 and 9. Besides this, in Dalian, respondents had a slightly higher preference for SAVs in terms of automation for social trips as shown in Figures 7 and 10. A prior study conducted in Lahore on mobile app taxi services revealed that Careem and Uber were preferred by $78 \%$ and $75 \%$ of respondents, respectively. In addition, the respondents reported that mobile app taxis were more reliable and safer than conventional public transportation [52]. It is thus arguable that, when SAVs enter the market, the share of these dynamic riding services will significantly increase.

\subsection{Discrete Choice Models}

4.2.1. Generic Variables and Goodness-of-Fit of the Models' Results. As outlined in Section 3.5, discrete choice models were used for data analysis and calibration. NLOGIT software was used for estimating the model parameters and for testing the goodness-of-fit. Analysis of the MNL model was provided first, as it was simpler and easier to interpret the model. All the alternative-specific and sociodemographic variables were considered for possible inclusion in this model, and were included in the final model if they were found to be significant at the $90 \%$ level $(p<0.10)$.

A summary of the results for Lahore is provided in Table 6, in which it can be seen that travel time, travel cost, waiting time, and walking distance are all significant and have negative coefficients. The negative sign of these 

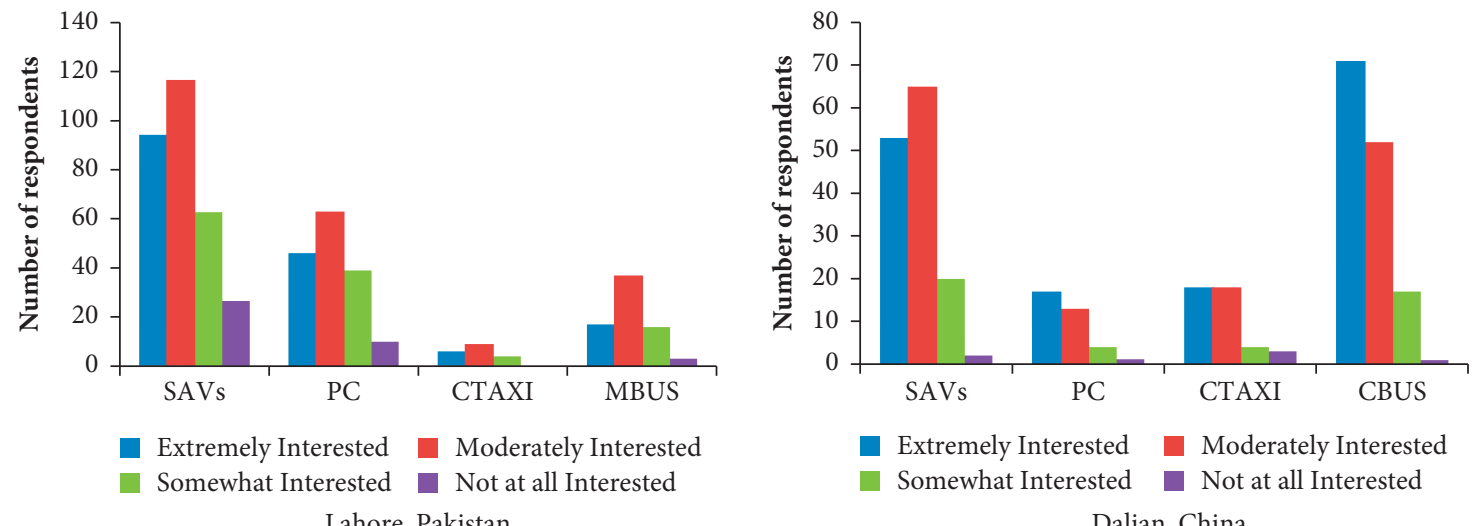

FIGURE 5: Preferences of automation interested individuals to schooling and working trips
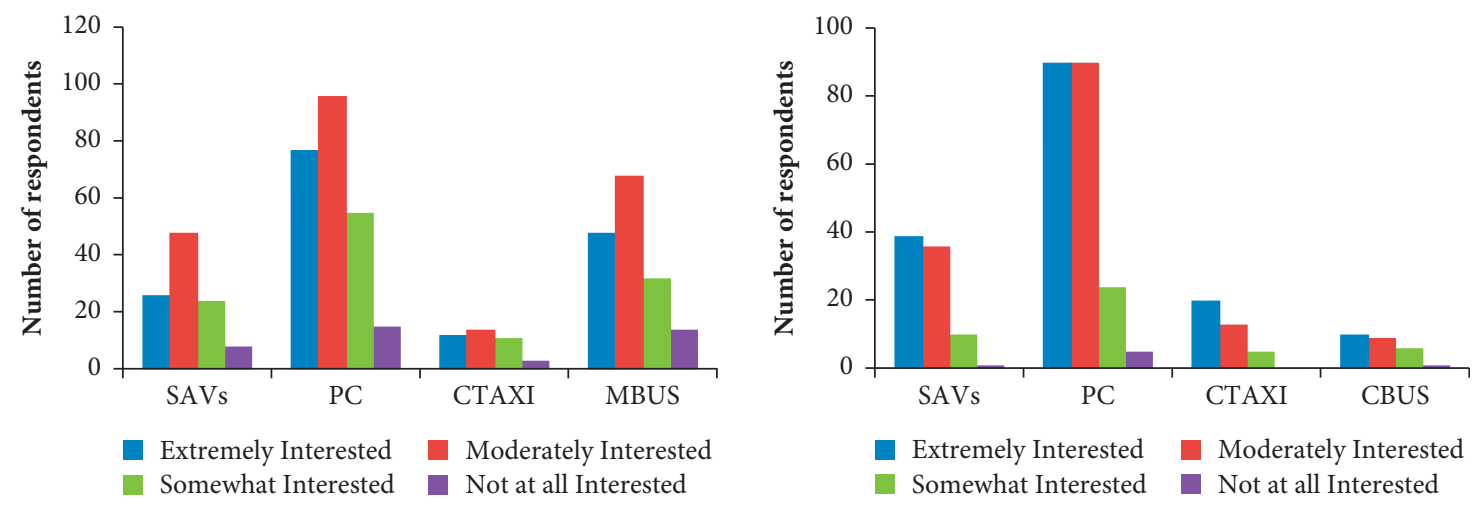

Lahore, Pakistan

Dalian, China

FIGURE 6: Preferences of automation interested individuals to shopping trips

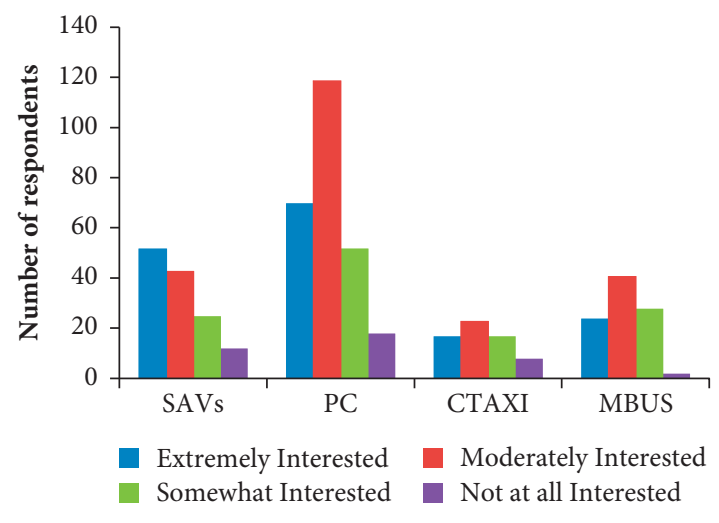

Lahore, Pakistan

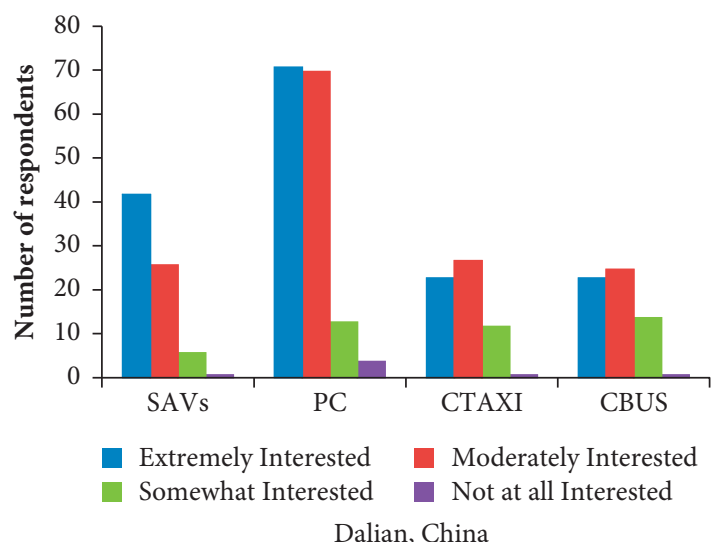

Dalian, China

FIgURE 7: Preferences of automation interested individuals to social trips

parameters is expected, as the utility and the choice probability decrease when the travel cost, travel time, and walking distance increase. A summary of the results for Dalian is provided in Table 7 , where it can be seen that the waiting time, travel time, and travel cost all have negative coefficients. As outlined above, these observations are unsurprising: people tend to choose the mode of transportation that has the minimum travel time and travel cost. This result is also consistent with the results of previous studies [29].
The MNL model is based on the assumption of independent irrelevant alternatives (IIA) and homogeneous responses. The MMNL model can relax these assumptions, potentially resulting in a better model. The MMNL model with panel effect was employed to capture the correlation of the repeated observations. This estimation is important for the analysis since SP survey respondents always provide multiple responses and are not independent from one another. Therefore, the panel effect should take into account the 


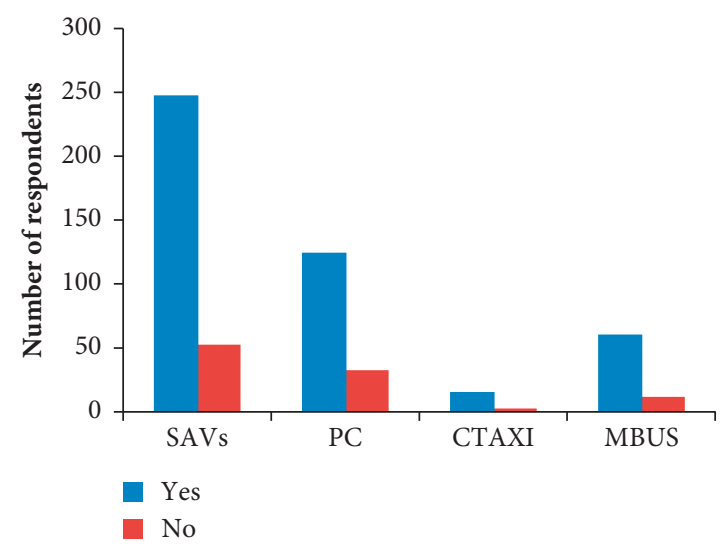

Lahore, Pakistan

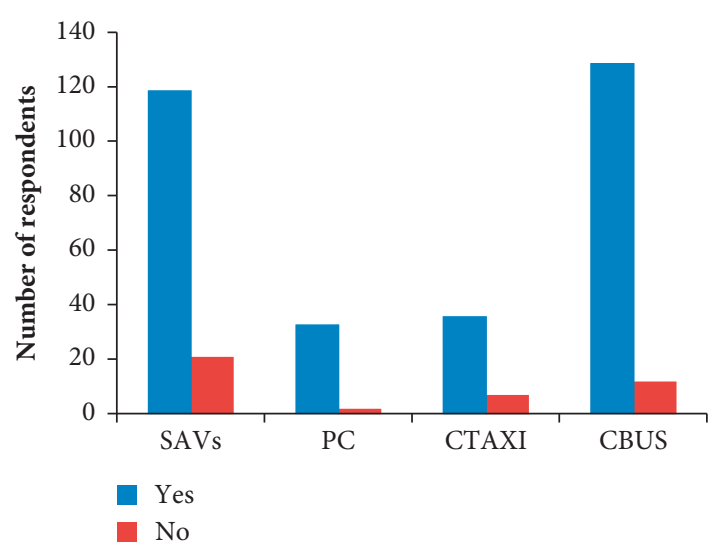

Dalian, China

Figure 8: Preferences of shared mobility interested individuals to schooling and working trips.

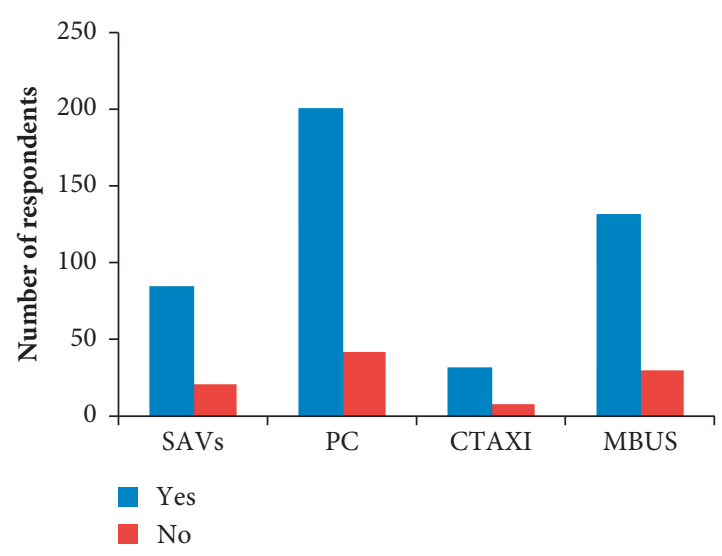

Lahore, Pakistan

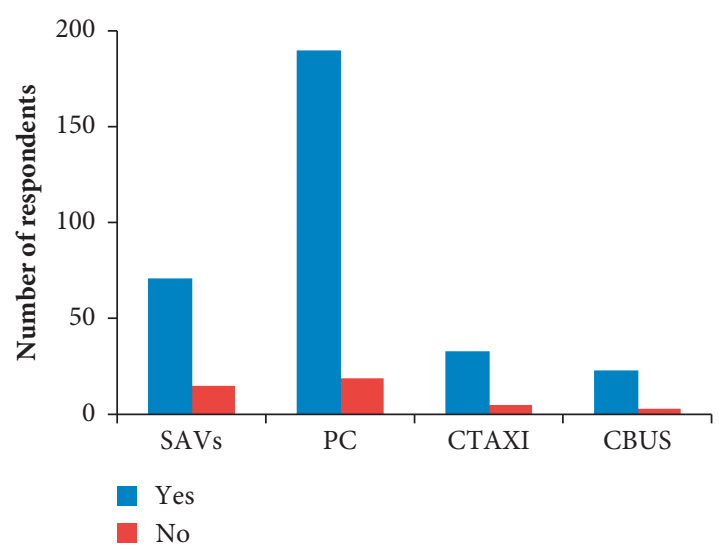

Dalian, China

Figure 9: Preferences of shared mobility interested individuals to shopping trips.

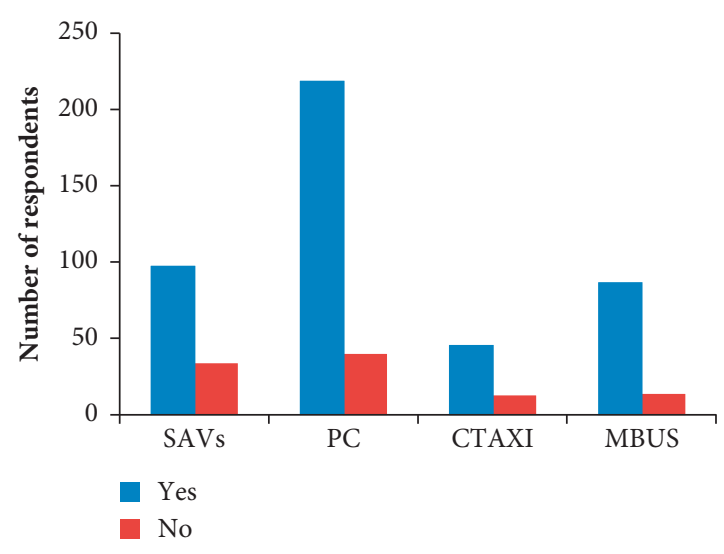

Lahore, Pakistan

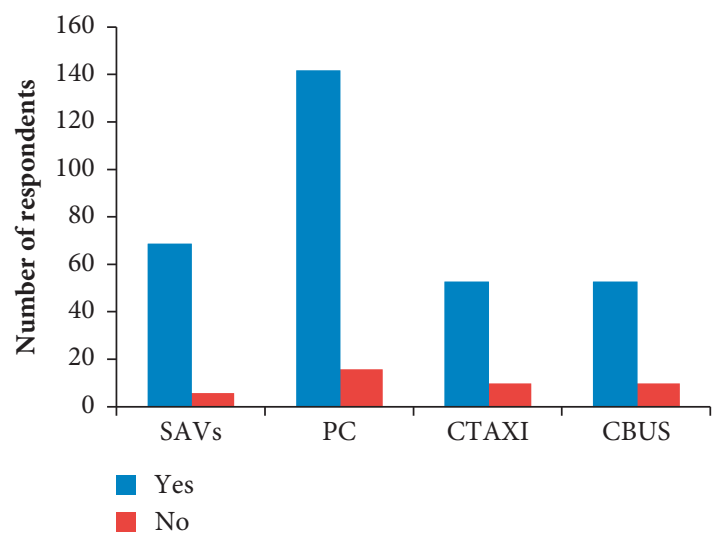

Dalian, China

FIgURE 10: Preferences of shared mobility interested individuals to social trips.

improvement of the fit. These two models were evaluated for the four modes of transportation in both cities. The results, provided in Tables 6 and 7, indicate that the panel MMNL model provides a slightly better fit in both cases. In particular, the pseudo $R^{2}$ values for the panel MMNL model were higher than the corresponding values for the MNL model. According to McFadden, estimates from the MMNL model are more robust than those from the MNL model [53]. The panel MMNL is preferable over MNL based on McFadden pseudo $R^{2}$ and the log-likelihood value as depicted in Tables 6 and 7 .

The panel MMNL model was fitted using a lognormal distribution for the alternative-specific variables, after 
TABle 6: Model estimates for Lahore, Pakistan.

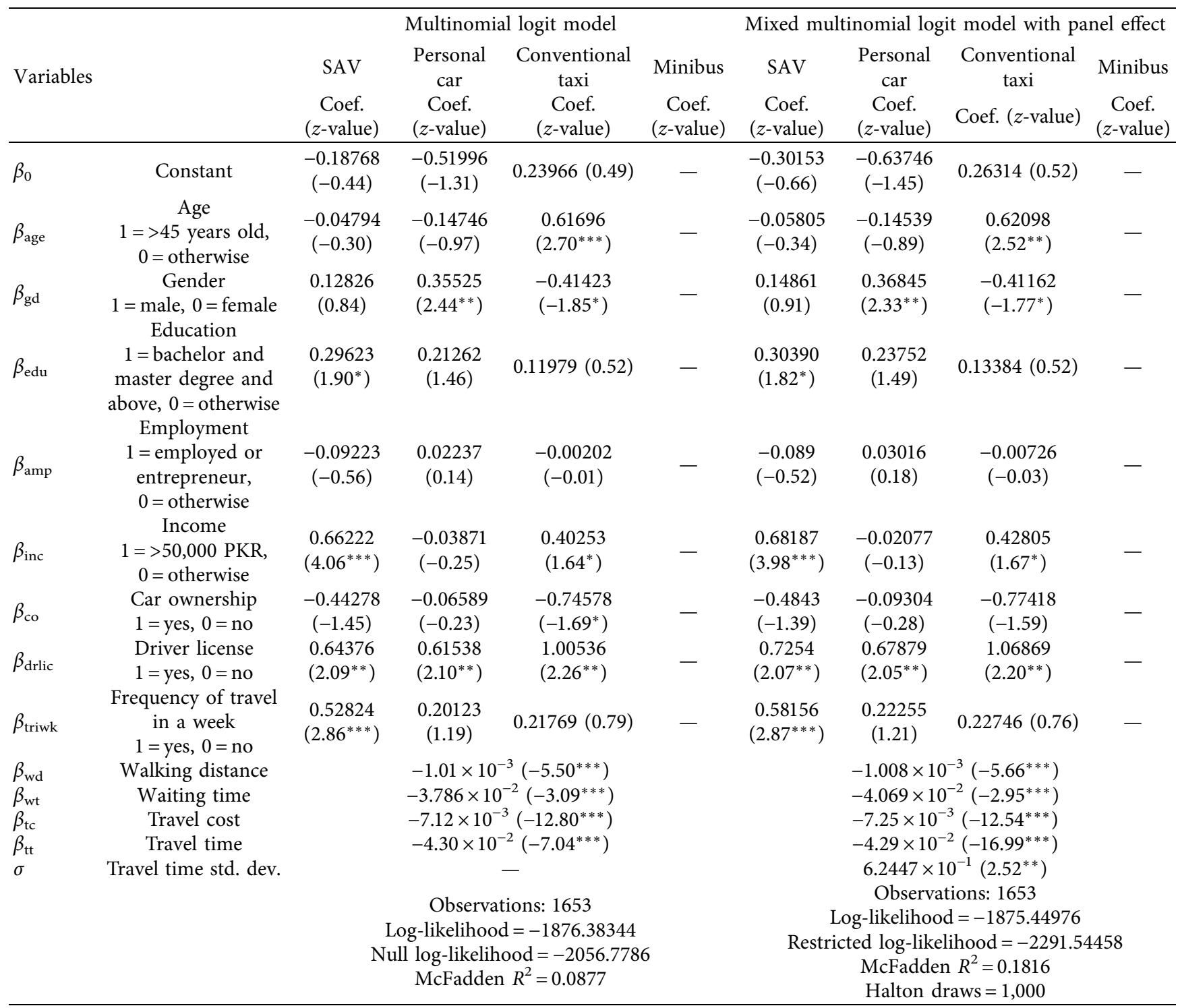

Note: ${ }^{* * *},{ }^{* *}$, and ${ }^{*}$ denotes statistical significance at $1 \%, 5 \%$, and $10 \%$ level respectively.

testing several different distributions for these parameters. In particular, specifying a lognormal distribution for the travel time yielded the best model output. The lognormal distribution is bounded by a positive value $(0,1)$. It is assumed that the opposite of travel time follows a lognormal distribution. Let the coefficient of the opposite of travel time be $\beta$, then the distribution of $\beta_{m t t}$ is:

$$
\beta_{m t t}=\exp \left(\beta+\sigma v_{m t t}\right)
$$

$\beta$ and $\sigma$ are parameters that need to be estimated, and $v_{\mathrm{mtt}}$ is a stochastic error, which follows a standard normal distribution. Since $v_{\mathrm{mtt}}$ follows a standard normal distribution, if we do not consider the impact of $v_{\mathrm{mtt}}$, on average, the coefficient of travel time is $\beta_{t t}=-\exp (\beta)$.

Tables 6 and 7 show that the coefficients of travel time and travel cost are negative as expected. The standard deviations (sigma) of the travel time coefficient are statistically significant, verifying that there is heterogeneity in the population. The conventional approach to simulation estimation is to use random draws from the specified distribution. A good performance in simulation estimation usually requires large numbers of draws, which require a large amount of computation. Bhat has found that a Halton sequence with a far small number of replications is often as effective as a far larger number of random draws [54]. Therefore, we used the Halton draws for the simulation of the mixed logit model. To achieve stable results for variables, 1,000 Halton draws were used. The lognormal distributions of travel time in Lahore and Dalian are presented in Figure 11. In Dalian, the standard deviations of travel time are more deviated from the mean than in Lahore. This long tail right-hand skew is the main drawback of the lognormal distribution, which generates 
Table 7: Model estimates for Dalian, China.

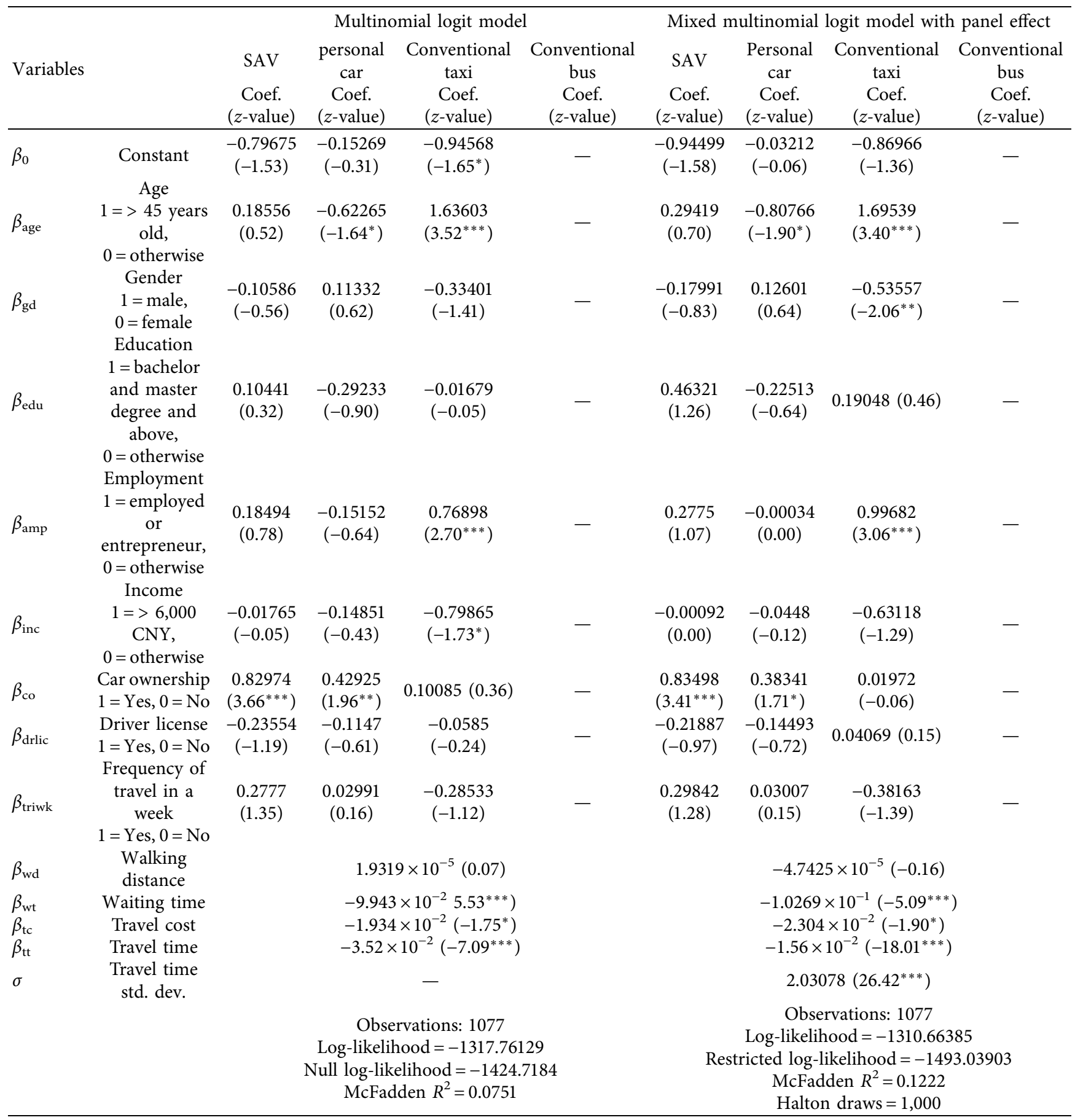

Note: ${ }^{* * *},{ }^{* *}$, and ${ }^{*}$ denotes statistical significance at $1 \%, 5 \%$, and $10 \%$ level respectively.

an overestimation of standard deviations. Despite its limitations, the lognormal distribution is preferred over normal distribution in the case of coefficients with a strong priori sign assumption, such as travel cost and travel time coefficients [55].

4.2.2. Sociodemographic Variables Results. The model estimates for the sociodemographic variables are provided in Tables 6 and 7, and a descriptive interpretation of these estimates is summarized in Table 8 . In terms of age, elderly people were more likely to use a conventional taxi than other modes of travel in Lahore. The results show counterintuitive behavior of the respondents, as the conventional taxi is an expensive mode of transportation in Lahore. This can be explained by the fact that elderly people rely on other family members and drivers in Pakistan. The conventional taxi drivers assist passengers, such as dropping passenger's luggage at the doorstep rather than other public 

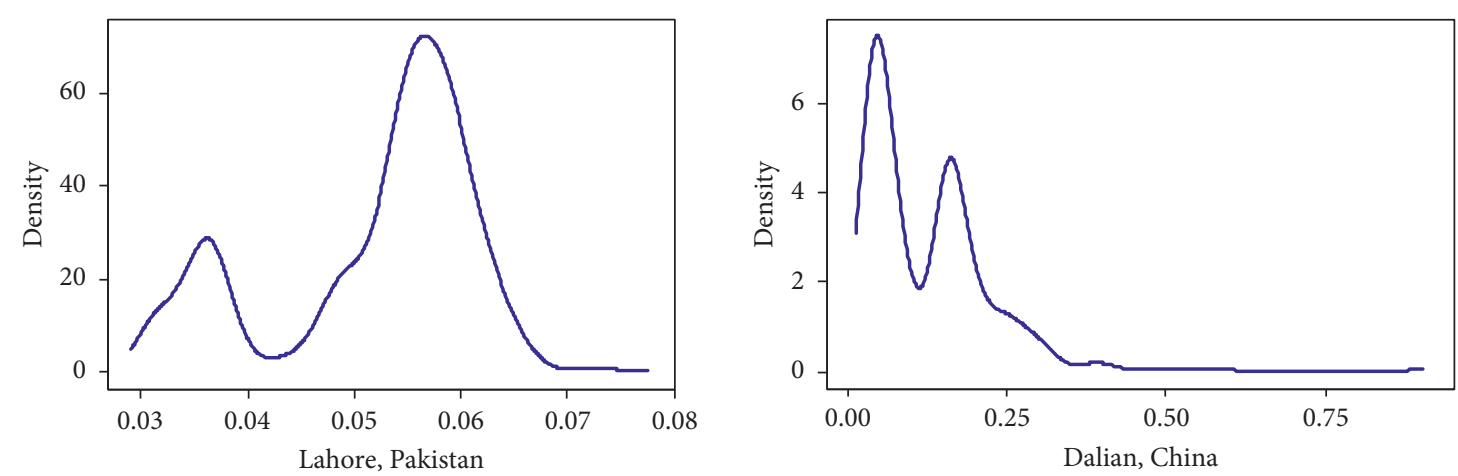

Figure 11: Distribution of travel time in Lahore and Dalian.

TABle 8: Explanation of sociodemographic factors in Lahore and Dalian.

\begin{tabular}{|c|c|c|c|c|}
\hline \multirow{2}{*}{ Factor } & \multicolumn{2}{|r|}{ Lahore } & \multicolumn{2}{|r|}{ Dalian } \\
\hline & Sign & Explanation & Sign & Explanation \\
\hline Education & + & $\begin{array}{l}\text { This implies that people having bachelor's and } \\
\text { master's degrees and above were more likely to } \\
\text { choose SAVs. This result is consistent with previous } \\
\text { studies that highly educated people are more aware of } \\
\text { new technologies. In developed countries such as the } \\
\text { USA, Israel, and the Netherlands, the findings of } \\
\text { other studies revealed that highly educated people } \\
\text { were more likely to use SAVs }[4,60] \text {. }\end{array}$ & - & Insignificant for SAVs. \\
\hline Income & + & $\begin{array}{l}\text { This indicates that people with higher incomes (i.e., a } \\
\text { monthly income }>50,000 \text { PKR) were more likely to } \\
\text { use SAVs. This observation is intuitive because the } \\
\text { high-income public is more likely to explore new } \\
\text { modes of transportation. Higher earners typically also } \\
\text { care more strongly about the principal advantages of } \\
\text { SAVs, such as the reduced risk of accidents and } \\
\text { environmental benefits. This result is also in line with } \\
\text { a previous study conducted in developed countries } \\
\text { that higher-income people were more likely to use } \\
\text { SAVs [60]. }\end{array}$ & - & Insignificant for SAVs. \\
\hline Car ownership & - & Insignificant for SAVs. & + & $\begin{array}{l}\text { This indicates that people who had their private cars } \\
\text { were more likely to use SAVs. This is likely due to } \\
\text { the perception that SAVs could provide the same } \\
\text { level of convenience and on-demand service but } \\
\text { without the cost associated with car ownership. In } \\
\text { addition, this positive behavior of respondents } \\
\text { indicated that they would use SAVs and give up the } \\
\text { existing private vehicles. }\end{array}$ \\
\hline Driver license & + & $\begin{array}{l}\text { This suggests that people with driver's licenses were } \\
\text { more likely to use SAVs. }\end{array}$ & - & Insignificant for SAVs. \\
\hline $\begin{array}{l}\text { Frequency of } \\
\text { travel in a week }\end{array}$ & + & $\begin{array}{l}\text { This implies that people who traveled more than two } \\
\text { days a week were more likely to use SAVs. This } \\
\text { finding reaffirmed the preference of people who were } \\
\text { used to conventional taxis for their trips. They are } \\
\text { thus likely to be attracted by SAVs, which represent } \\
\text { an advanced form of taxis that will eliminate the } \\
\text { walking distance and decrease the waiting of the users } \\
\text { and provide door-to-door services. }\end{array}$ & - & Insignificant for SAVs. \\
\hline
\end{tabular}

transportation services. In Pakistan, the fare is often set by open negotiations between the passenger and the driver, and it is primarily dependent on the driver's mood, location, and time. In Dalian, elder people were also more likely to use the conventional taxi. Dalian's conventional taxi is slightly more expensive than other existing travel modes, and the fare is calculated on a taximeter that charges by both time and distance. The younger people, however, expressed more inclination to use private cars in Dalian. 
From the perspective of gender, men were perceived as more likely to use private cars in Lahore. This observation is not surprising because family owned private cars were primarily used by men in Pakistan. On the other hand, it was found that women were more likely to use conventional taxis. This is in stark contrast with a previous study's finding that women did not hire taxis due to cultural norms and privacy constraints [56]. It can be partly explained by the fact that women in Pakistan are marginalized due to privacy constraints and have restricted transit options. Due to limited public transportation options, women usually prefer to take traditional taxis and ride-sharing services [57]. The SAVs will overcome these issues and provide an alternative form of private transportation. It has been expected that women will prefer SAVs when they are practically viable. On the other hand, no such gender disparity in transit options was found in Dalian.

In Dalian, employment was also found to have a significant positive relationship with the endogenous variable, suggesting that employed people and entrepreneurs were more likely to use a conventional taxi. This is reasonable because taxis allow people to perform other tasks while traveling, making time spent on traveling more desirable and more valuable. In contrast, in Lahore, employment was found to be insignificantly associated with any of the transportation alternatives.

The association between education and the endogenous variable was positive and significant in Lahore, implying that people having bachelor's degrees and above were more likely to choose SAVs. Conversely, the education variable was found to be insignificantly associated with any of the transportation alternatives in Dalian. There was a significant positive association between income and the endogenous variable in Lahore, but not in Dalian. In Dalian, private car ownership was found to have a significant association with a preference for SAVs. This positive behavior of respondents indicates that they would use SAVs and give up the existing private vehicles. This finding contradicts a previous US study which found that $18.6 \%$ people were likely and $7.3 \%$ were extremely likely to relinquish an existing vehicle [30].

In Lahore, people with driver's licenses were significantly more likely to use SAVs, private cars, and conventional taxis. In contrast, in Dalian, possession of a driver's license was found to be insignificantly associated with any of the transportation alternatives. In addition, people who traveled more than two days a week were more likely to use SAVs in Lahore. The people in Lahore are reluctant to take public transportation due to disintegrating land-use mismanagement and a cumbersome public transportation system. For these reasons, private cars and motorcycles are the dominant modes of transportation in Lahore. The result supports the preference of people who would use SAVs to travel in the future to get rid of recurrent public transportation issues in Lahore. On the other hand, in Dalian, the frequency of travel in a week was perceived to be insignificantly associated with any of the transportation alternatives.

The value of travel time saving (VTTS) is a core concept of transportation demand modeling and appraisal. The
VTTS depends on several parameters and varies from country to country, from industry to industry, and even from person to person, based on socioeconomic factors, the purpose of travel, the length of travel, etc. [58]. The VTTS is calculated as the ratio between the coefficient of travel time and the coefficient of travel cost parameters. In Lahore, the coefficient value of travel cost is $\beta_{\mathrm{tc}}=-0.00725$, and the travel time coefficient is $\beta_{\mathrm{tt}}=-0.0429$, resulting in an average VTTS of 5.917 PKR/min or $355 \mathrm{PKR} / \mathrm{hr}(\$ 2.28 / \mathrm{hr})$ across all modes. Likewise, in Dalian, the travel cost coefficient is $\beta_{\mathrm{tc}}=-0.02304$, and the travel time coefficient is $\beta_{\mathrm{tt}}=-0.0156$, resulting in an average VTTS of $0.677 \mathrm{CNY} / \mathrm{min}$ or 40.62 $\mathrm{CNY} / \mathrm{hr}(\$ 6.36 / \mathrm{hr})$ across all modes. For comparison, the VTTS in the United Kingdom is 11.7 pounds/hr $(\$ 16.51 / \mathrm{hr})$ across all modes with an average distance of $12.87 \mathrm{~km}$ [59].

\section{Conclusions}

This study aimed to examine the public attitude toward the adoption of SAVs in a cross-national context, and an SP survey was performed to capture the travel mode preferences of respondents in the cities of Lahore (Pakistan) and Dalian (China). The SP surveys contained detailed information on socio-demographic attributes of travelers and service attributes of the four travel mode choices considered, i.e., SAVs, private car, taxi, and bus. The MNL model and the MMNL model were used for model estimation. Model estimation results showed that the MMNL model was more robust than the MNL model in predicting the travel mode choice.

The findings of the study revealed that generic attributes such as travel time, waiting time, and travel cost have a significant influence on transportation preferences in both cities. In addition, the results showed that highly educated people with high incomes were more likely to use SAVs in Lahore. The study also suggested that people in the city of Lahore who traveled more than two days a week and had driver's licenses were more likely to use SAVs. Based on our inference, private vehicles and motorcycles in the city could be replaced by bike-sharing, e-bikes, and car-sharing to achieve a sustainable transportation system. Surprisingly, in Dalian, only one sociodemographic variable, i.e., car ownership, was found to be significant for the preference of SAVs. This implies that people who had their private cars were more likely to use SAVs. This positive behavior of respondents indicated that people in Dalian were more likely to give up their private vehicles when SAVs practically come into the market. It is an interesting result that in developed countries such as the USA, the majority of people still prefer private cars to travel [30]. The descriptive results also showed that respondents had slightly higher preferences for SAVs for different trip purposes due to sharing of SAVs rather than automation in both cities. This result demonstrates that the public is accustomed to shared mobility options and is wary of an autonomous vehicle. The findings of this study will provide a useful benchmark for policymakers tasked with devising effective policies for the future implementation and deployment of SAVs in cities worldwide.

The study has a few limitations that must be acknowledged. First, the percentage of students and younger 
respondents was high, which might cause bias in analyzing the behavior of respondents. Therefore, revealed preference surveys and stratified sampling should be considered in future research. Second, this study was first conducted in Pakistan and focused only on SAVs, private cars, conventional taxis, and minibuses in Lahore, ignoring other modes such as motorcycle, walking, and BRT to reduce the cognitive burden and complexity of the survey. Forthcoming studies can emphasize all modes of transportation to exhaustively capture the preferences of respondents.

\section{Data Availability}

The data are available on request from the corresponding author.

\section{Conflicts of Interest}

The authors declare no conflict of interest.

\section{Acknowledgments}

This research was supported by the National Key Research and Development Program of China (Project no. 2018YFB1600900), the National Natural Science Foundation of China (Project nos. 71971038 and 71701030), the $\mathrm{Hu}-$ manities and Social Sciences Youth Foundation of the Ministry of Education of China (Project no. 17YJCZH265), and the Fundamental Research Funds for the Central Universities of China (Project no. DUT20GJ210).

\section{References}

[1] P. Jing, H. Huang, B. Ran, F. Zhan, and Y. Shi, "Exploring the factors affecting mode choice intention of autonomous vehicle based on an extended theory of planned behavior-a case study in China," Sustainability, vol. 11, no. 4, Article ID 1155, 2019.

[2] D. J. Fagnant and K. M. Kockelman, "The travel and environmental implications of shared autonomous vehicles, using agent-based model scenarios," Transportation Research Part C: Emerging Technologies, vol. 40, pp. 1-13, 2014.

[3] D. J. Fagnant and K. Kockelman, "Preparing a nation for autonomous vehicles: opportunities, barriers and policy recommendations," Transportation Research Part A: Policy and Practice, vol. 77, pp. 167-181, 2015.

[4] C. J. Haboucha, R. Ishaq, and Y. Shiftan, "User preferences regarding autonomous vehicles," Transportation Research Part C: Emerging Technologies, vol. 78, pp. 37-49, 2017.

[5] I. Ullah, A. Jamal, and F. Subhan, "Public perception of autonomous car: a case study for Pakistan," Advances in Transportation Studies, vol. 49, pp. 145-154, 2019.

[6] J. B. Greenblatt and S. Shaheen, "Automated vehicles, on-demand mobility, and environmental impacts," Current sustainable/renewable energy reports, vol. 2, no. 3, pp. 74-81, 2015.

[7] A. Faisal, M. Kamruzzaman, T. Yigitcanlar, and G. Currie, "Understanding autonomous vehicles," Journal of Transport and Land Use, vol. 12, no. 1, pp. 45-72, 2019.

[8] J. Kamel, R. Vosooghi, J. Puchinger, F. Ksontini, and G. Sirin, "Exploring the impact of user preferences on shared autonomous vehicle modal split: a multi-agent simulation approach," Transportation Research Procedia, vol. 37, pp. 115-122, 2019.

[9] C. Pakusch, G. Stevens, A. Boden, and P. Bossauer, "Unintended effects of autonomous driving: a study on mobility preferences in the future," Sustainability, vol. 10, no. 7, Article ID 2404, 2018.

[10] P. Ashkrof, G. Homem de Almeida Correia, O. Cats, and B. van Arem, "Impact of automated vehicles on travel mode preference for different trip purposes and distances," Transportation Research Record: Journal of the Transportation Research Board, vol. 2673, no. 5, pp. 607-616, 2019.

[11] T. Wellik and K. Kockelman, "Anticipating land-use impacts of self-driving vehicles in the Austin, Texas, region," Journal of Transport and Land Use, vol. 13, no. 1, pp. 185-205, 2020.

[12] T. Litman, "Autonomous vehicle implementation predictions," Victoria Transport Policy Institute, vol. 28, 2014.

[13] A. Soteropoulos, M. Berger, and F. Ciari, "Impacts of automated vehicles on travel behaviour and land use: an international review of modelling studies," Transport Reviews, vol. 39, no. 1, pp. 29-49, 2019.

[14] D. Milakis, B. Van Arem, and B. Van Wee, "Policy and society related implications of automated driving: a review of literature and directions for future research," Journal of Intelligent Transportation Systems, vol. 21, no. 4, pp. 324-348, 2017.

[15] S. Zhong, Y. Gong, Z. Zhou, R. Cheng, and F. Xiao, “Active learning for multi-objective optimal road congestion pricing considering negative land use effect," Transportation Research Part C: Emerging Technologies, vol. 125, Article ID 103002, 2021.

[16] S. Zhong, R. Cheng, X. Li, Z. Wang, and Y. Jiang, "Identifying the combined effect of shared autonomous vehicles and congestion pricing on regional job accessibility," Journal of Transport and Land Use, vol. 13, no. 1, pp. 273-297, 2020.

[17] S. Narayanan, E. Chaniotakis, and C. Antoniou, "Shared autonomous vehicle services: a comprehensive review," Transportation Research Part C: Emerging Technologies, vol. 111, pp. 255-293, 2020.

[18] I. Overtoom, G. Correia, Y. Huang, and A. Verbraeck, "Assessing the impacts of shared autonomous vehicles on congestion and curb use: a traffic simulation study in the Hague, Netherlands," International Journal of Transportation Science and Technology, vol. 9, no. 3, pp. 195-206, 2020.

[19] P. Muhammad Tahir Masood PhD, "Transportation problems in developing countries Pakistan: a case-in-point," International Journal of Business and Management, vol. 6, no. 11, pp. 256-266, 2011.

[20] M. S. Ali, M. Adnan, S. M. Noman, and S. F. A. Baqueri, "Estimation of traffic congestion cost-a case study of a major arterial in Karachi," Procedia Engineering, vol. 77, pp. 37-44, 2014.

[21] A. Aziz, M. S. Nawaz, M. Nadeem, and L. Afzal, "Examining suitability of the integrated public transport system: a case study of Lahore," Transportation Research Part A: Policy and Practice, vol. 117, pp. 13-25, 2018.

[22] M. A. Javid, T. Mehmood, H. M. Asif, A. U. Vaince, and M. Raza, "Travelers' attitudes toward carpooling in Lahore: motives and constraints," Journal of Modern Transportation, vol. 25, no. 4, pp. 268-278, 2017.

[23] R. Mu and M. De Jong, "A tale of two Chinese transit metropolises and the implementation of their policies: shenyang and Dalian (Liaoning Province, China)," Energies, vol. 11 , no. 3, p. 481, 2018.

[24] V. Tran, S. Zhao, E. B. Diop, and W. Song, “Travelers' acceptance of electric carsharing systems in developing 
countries: the case of China," Sustainability, vol. 11, no. 19, Article ID 5348, 2019.

[25] F. Kuhnert, C. Stürmer, and A. Koster, Five Trends Transforming the Automotive Industry, pp. 1-48, PricewaterhouseCoopers $\mathrm{GmbH}$ Wirtschaftsprüfungsgesellschaft, Berlin, Germany, 2018.

[26] K. Winter, O. Cats, K. Martens, and B. van Arem, "A stated-choice experiment on mode choice in an era of free-floating carsharing and shared autonomous vehicles," in Proceedings of the 96th Annual Meeting Transportation Research Board, no. -, Washington, DC, USA, January 2017.

[27] P. Bansal, K. M. Kockelman, and A. Singh, "Assessing public opinions of and interest in new vehicle technologies: an Austin perspective," Transportation Research Part C: Emerging Technologies, vol. 67, pp. 1-14, 2016.

[28] M. Cools, C. Rongy, and S. Limbourg, "Can autonomous vehicles reduce car mobility? evidence from a stated adaptation experiment in Belgium," in Proceedings of the Transportation Research Board Annual Meeting, Washington, DC, USA, January 2017.

[29] R. Krueger, T. H. Rashidi, and J. M. Rose, "Preferences for shared autonomous vehicles," Transportation Research Part C: Emerging Technologies, vol. 69, pp. 343-355, 2016.

[30] N. Menon, N. Barbour, Y. Zhang, A. R. Pinjari, and F. Mannering, "Shared autonomous vehicles and their potential impacts on household vehicle ownership: an exploratory empirical assessment," International Journal of Sustainable Transportation, vol. 13, no. 2, pp. 111-122, 2019.

[31] Z. Wadud and F. Y. Huda, "Fully automated vehicles: the use of travel time and its association with intention to use," -Transport, vol. 13, pp. 1-15, 2020.

[32] M. D. Yap, G. Correia, and B. Van Arem, "Preferences of travellers for using automated vehicles as last mile public transport of multimodal train trips," Transportation Research Part A: Policy and Practice, vol. 94, pp. 1-16, 2016.

[33] M. Kyriakidis, R. Happee, and J. C. F. de Winter, "Public opinion on automated driving: results of an international questionnaire among 5000 respondents," Transportation Research Part F: Traffic Psychology and Behaviour, vol. 32, pp. 127-140, 2015.

[34] S. Nordhoff, J. De Winter, M. Kyriakidis, B. Van Arem, and R. Happee, "Acceptance of driverless vehicles: results from a large cross-national questionnaire study," Journal of Advanced Transportation, vol. 2018, Article ID 5382192, 22 pages, 2018.

[35] I. Sanaullah, A. Hussain, A. Chaudhry, K. Case, and M. Enoch, "Autonomous vehicles in developing countries: a case study on user's view point in Pakistan," Advances in Intelligent Systems and Computing, Springer, Berlin, Germany, pp. 561-569, 2017.

[36] B. Schoettle and M. Sivak, Public Opinion about Self-Driving Vehicles in China, India, Japan, the US, the UK, and Australia, University of Michigan, Ann Arbor, Michigan, 2014.

[37] E. J. Zolnik, A. Malik, and Y. Irvin-Erickson, "Who benefits from bus rapid transit? evidence from the Metro Bus System (MBS) in Lahore," Journal of Transport Geography, vol. 71, pp. 139-149, 2018.

[38] S. Zhong and M. Bushell, "Impact of the built environment on the vehicle emission effects of road pricing policies: a simulation case study," Transportation Research Part A: Policy and Practice, vol. 103, pp. 235-249, 2017.

[39] S. Zhong, Y. Jiang, and O. A. Nielsen, "Lexicographic multi-objective road pricing optimization considering land use and transportation effects," European Journal of Operational Research, 2021, (in press).

[40] R. Mu, M. de Jong, B. Yu, and Z. Yang, "The future of the modal split in China's greenest city: assessing options for integrating Dalian's fragmented public transport system," Policy and Society, vol. 31, no. 1, pp. 51-71, 2012.

[41] J. Liu, S. Zhong, Y. Huang, and Z. Wang, "How does the preference heterogeneity affect the elderly's evaluation of bus accessibility? Evidence from Guangzhou, China," Journal of Transport \& Health, vol. 22, Article ID 101094, 2021.

[42] G. Correia and J. M. Viegas, "Carpooling and carpool clubs: clarifying concepts and assessing value enhancement possibilities through a stated preference web survey in Lisbon, Portugal," Transportation Research Part A: Policy and Practice, vol. 45, no. 2, pp. 81-90, 2011, (in English).

[43] S. Hess and J. M. Rose, "Some lessons in stated choice survey design," European Transport Conference, vol. 14, 2009.

[44] L. Márquez, J. J. Soto, and L. F. Macea, "Willingness to change car use to commute to the UPTC main campus, Colombia," Journal of Transport and Land Use, vol. 12, no. 1, pp. 335-353, 2019.

[45] M. Javid, "Influence of situational constraints and public transport incentives on acceptability of car use restrictions in Lahore, Pakistan," Proceedings of the Pakistan Academy of Sciences, vol. 52, no. 2, pp. 109-116, 2015.

[46] Y. Liu, J. Chen, W. Wu, and J. Ye, "Typical combined travel mode choice utility model in multimodal transportation network," Sustainability, vol. 11, no. 2, p. 549, 2019.

[47] G. H. d. A. Correia, E. Looff, S. van Cranenburgh, M. Snelder, and B. van Arem, "On the impact of vehicle automation on the value of travel time while performing work and leisure activities in a car: theoretical insights and results from a stated preference survey," Transportation Research Part A: Policy and Practice, vol. 119, pp. 359-382, 2019.

[48] F. Steck, V. Kolarova, F. Bahamonde-Birke, S. Trommer, and B. Lenz, "How autonomous driving may affect the value of travel time savings for commuting," Transportation Research Record: Journal of the Transportation Research Board, vol. 2672, no. 46, pp. 11-20, 2018.

[49] S. Hess and J. W. Polak, "Mixed Logit modelling of parking type choice behaviour," Transportation Statistics, JD Ross Publishing, Plantation, FL, USA, 2009.

[50] R. B. Noland, H. Park, L. A. Von Hagen, and D. G. Chatman, "A mode choice analysis of school trips in New Jersey," Journal of Transport and Land Use, vol. 7, no. 2, pp. 111-133, 2014.

[51] A. Jana, A. Sarkar, J. V. Kallakurchi, and S. Kumar, "Autonomous vehicle as a future mode of transport in India: analyzing the perception, opportunities and hurdles," in Proceedings of the Eastern Asia Society for Transportation Studies, Tokyo, Japan, December 2019.

[52] R. Rasheed, F. Mazhar, and M. Shahid, "Mobile appbased taxi services and customer satisfaction: an empirical review form Lahore city, Pakistan," Internationa Journal of Economics, Commerce and Management, vol. 6, no. 5, pp. 330-340, 2018.

[53] P. H. Hoang, S. Zhao, and S. E. Houn, "Motorcycle drivers' parking lot choice behaviors in developing countries: analysis to identify influence factors," Sustainability, vol. 11, no. 9, Article ID 2463, 2019.

[54] C. R. Bhat, "Quasi-random maximum simulated likelihood estimation of the mixed multinomial logit model," Transportation Research Part B: Methodological, vol. 35, no. 7, pp. 677-693, 2001. 
[55] S. Hess, M. Bierlaire, and J. W. Polak, "Estimation of value of travel-time savings using mixed logit models," Transportation Research Part A: Policy and Practice, vol. 39, no. 2-3, pp. 221-236, 2005.

[56] I. Ullah, K. Liu, and T. Vanduy, "Examining travelers' acceptance towards car sharing systems-peshawar City, Pakistan," Sustainability, vol. 11, no. 3, Article ID 808, 2019.

[57] S. Iqbal, A. Woodcock, and J. Osmond, "The effects of gender transport poverty in Karachi" (in English)," Journal of Transport Geography, vol. 84, Article ID 102677, 2020.

[58] I. C. Athira, C. P. Muneera, K. Krishnamurthy, and M. V. L. R. Anjaneyulu, "Estimation of value of travel time for work trips," Transportation Research Procedia, vol. 17, pp. 116-123, 2016.

[59] Z. Wadud and P. K. Chintakayala, "To own or not to own-that is the question: the value of owning a (fully automated) vehicle," Transportation Research Part C: Emerging Technologies, vol. 123, Article ID 102978, 2021.

[60] K. Winter, O. Cats, K. Martens, and B. van Arem, "Identifying user classes for shared and automated mobility services," European Transport Research Review, vol. 12, pp. 1-11, 2020. 